\title{
The utility of Leventhal's model in the analysis of the psycho-behavioral implications of familial cancer - a literature review
}

\author{
Roxana Postolica ${ }^{1,2}$, Magdalena lorga $^{3}$, Mihaela Savin ${ }^{4}$, Doina Azoicai ${ }^{5}$, Violeta Enea ${ }^{6}$
}

\author{
${ }^{1}$ Institute of Oncology, lasi, Romania \\ 2Department of Oncogenetics, University of Medicine and Pharmacy "Gr. T. Popa" \\ of lasi, Iasi, Romania \\ ${ }^{3}$ University of Medicine and Pharmacy "Gr. T. Popa" Iasi, Iasi, Romania \\ ${ }^{4}$ Department of Psychology, Faculty of Human Sciences, University of Potsdam, \\ Potsdam, Germany \\ ${ }^{5}$ Department of Oncogenetics, University of Medicine and Pharmacy “Gr. T. Popa” \\ of lasi, lasi, Romania \\ 'Faculty of Psychology and Education Sciences, University "Alexandru Ioan Cuza" \\ of Iasi, lasi, Romania
}

Submitted: 30 May 2016

Accepted: 1 August 2016

Arch Med Sci 2018; 14, 5: 1144-1154

DOI: https://doi.org/10.5114/aoms.2016.63149

Copyright $\odot 2016$ Termedia \& Banach

\section{Abstract}

Introduction: We aim to highlight the utility of this model in the analysis of the psycho-behavioral implications of family cancer, presenting the scientific literature that used Leventhal's model as the theoretical framework of approach.

Material and methods: A systematic search was performed in six databases (EBSCO, ScienceDirect, PubMed Central, ProQuest, Scopus, and Web of Science) with empirical studies published between 2006 and 2015 in English with regard to the Common Sense Model of Self-Regulation (CSMR) and familial/hereditary cancer. The key words used were: illness representations, common sense model, self regulatory model, familial/hereditary/ genetic cancer, genetic cancer counseling. The selection of studies followed the PRISMA-P guidelines (Moher et al., 2009; Shamseer et al., 2015), which suggest a three-stage procedure.

Results: Individuals create their own cognitive and emotional representation of the disease when their health is threatened, being influenced by the presence of a family history of cancer, causing them to adopt or not a salutogenetic behavior. Disease representations, particularly the cognitive ones, can be predictors of responses to health threats that determine different health behaviors. Age, family history of cancer, and worrying about the disease are factors associated with undergoing screening. No consensus has been reached as to which factors act as predictors of compliance with cancer screening programs.

Conclusions: This model can generate interventions that are conceptually clear as well as useful in regulating the individuals' behaviors by reducing the risk of developing the disease and by managing as favorably as possible health and/or disease.

Key words: disease, Leventhal's model, family cancer, cancer screening, illness representation.

\author{
Corresponding author: \\ Magdalena lorga PhD \\ University of Medicine \\ and Pharmacy \\ "Gr. T. Popa" lasi \\ 7 Universitatii St \\ 700460 lasi, Romania \\ Phone: +40 722800936 \\ E-mail: magdaiorga@yahoo. \\ com
}




\section{Introduction}

The Self-Regulatory Model (SRM) [1-3] is a cognitive-affective model that highlights the existence of both emotional components as well as cognitive components; both of these components alter the perception of disease threat and influence each other. It is the emotional element that distinguishes the SRM from other theoretical models which explain the perception of disease and treatment and which only take the cognitive and/or behavioral component into consideration (e.g., Health Belief Model [4-6]; Theory of Reasoned Action [7]; Theory of Planned Behavior [8]). This parallel cognitive and emotional processing of the menace implied by the disease recommends using this model in studying cancer, an emotionally challenging disease for the patient and their entire family [3]. The Common Sense Model of Self-Regulation (CSMR) is a dynamic, complex system that highlights self-regulation of health and disease [9].

The cancer diagnosis is a difficult and worrying experience; it is life-disrupting, requires continuous adjustment and generates high levels of psychosocial distress in more than a third of patients $[10,11]$. At the same time, the disease can lead to family crisis, changing family dynamics and roles [12]. The patients and their families must continuously adjust to threats to their own identity: at first, when they receive the diagnosis, and later, to the treatment, to various physical symptoms, and to emotional distress. This adjustment is considered by the CSMR, in which the patient with cancer is considered to be actively seeking and processing information about the disease, building his/her own cognitive and emotional representations with regard to the disease, and finally selecting and applying those coping procedures that will help him/ her face the threat of disease $[13,14]$.

Advances in molecular genetics offer individuals the possibility of being tested for their susceptibility to developing certain types of cancer due to gene mutations. Oncogenetics and genetic testing can contribute to reducing the risk of developing the disease, improving health status, and, implicitly, reducing mortality in individuals with hereditary risk of cancer, as well as educating the population by facilitating understanding regarding the implications of genetic, psycho-social and behavioral factors for health and illness [15]. At the same time, it generates different attitudes towards knowing the risk of developing the disease and adopting specific consequent behavior [16]. These choices involve individual psychological, as well as socio-familial risks; therefore, genetic testing from the perspective of stress and adjustment is not simply a health behavior, but a way to cope with the stress caused by the risk of developing the disease, according to the CSMR $[17,18]$. From this perspective, the CSMR provides a comprehensive framework for identifying and analyzing the factors affecting decision making, adjustment to the decision to undergo genetic testing, management of the results of genetic tests, and adopting screening actions [19].

However, in several other studies this model is criticized or considered to be too limited. For example, Marteau and Weinman [17] recommend further developing the model so that it includes the already existing cognitive representations of health threats. At the same time, the behaviors related to salutogenesis and disease control imply different motivational processes. These processes can be generated by cognitions and emotions that are not directly related to illness perception. Therefore, it has been recommended to combine Leventhal's model with a motivational one [2022]. DiMateo [23] suggests including social support as a global concept in the analysis, with the purpose of accurately measuring the perceptions - including the factors involved in their genesis of disease and treatment.

The emotional impact of cancer on the patient and his/her family when there is a family history of cancer, the psychosocial and ethical issues raised by genetic testing - these are the factors that motivate us to research the way the CSMR is used in their analyses.

This review aims to summarize the literature that used the CSMR as the theoretical framework of approach in order to highlight the way in which this model, through its specificity (dynamic, individual-centered, self-regulating, oriented towards elaborating personalized therapy plans), can be used in analyzing the psycho-behavioral implications of familial cancer. The review is the first one in the field conforming to Marteau's theoretical analysis regarding the theory of self-regulation. It is proved that the utility of this theory has been ignored when it is about the understanding of choices made by individuals regarding the lack of reaction when they get information about health risks. Further studies, presented in our work, reach the common conclusion that individuals with high genetic risks regarding cancer disease who believe that healthy behavior could reduce the risk of developing cancer when there is a genetic component are less willing to have sanogenetic behavior.

This work shows the impact of CSMR on the construction of psycho-educational programs built to adopt a preventive and sanogenetic lifestyle.

\section{Material and methods}

We conducted a systematic search in six databases (EBSCO, ScienceDirect, PubMed Central, ProQuest, Scopus, and Web of Science) with the purpose of identifying any empirical studies pub- 


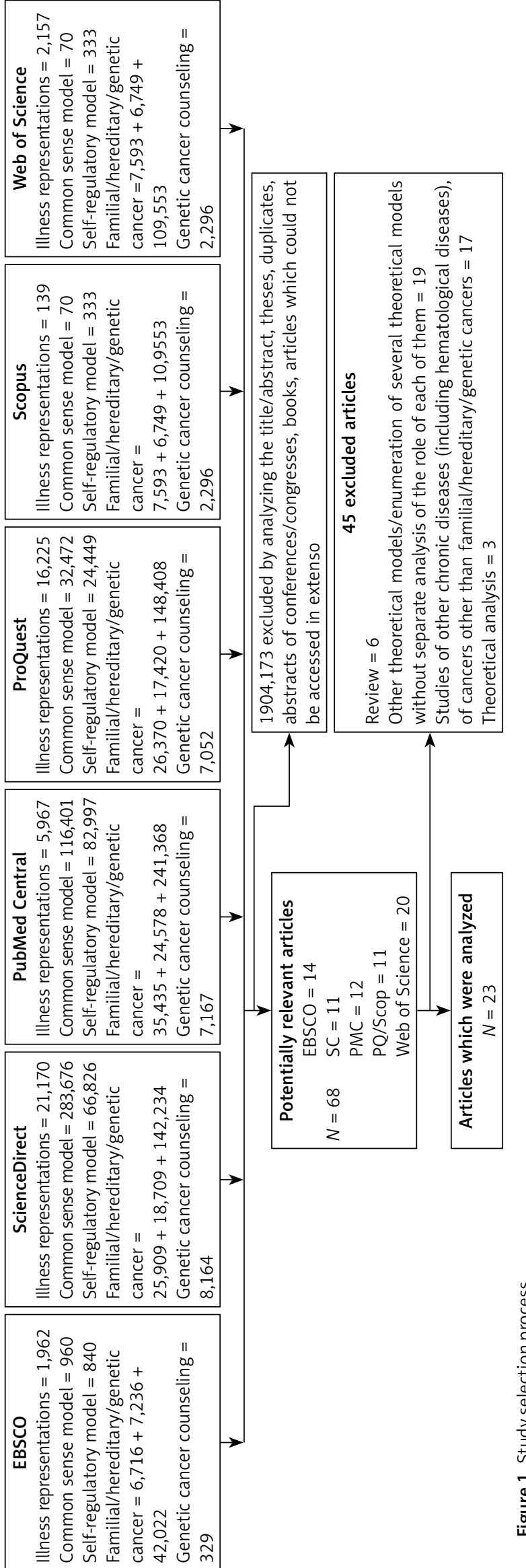

lished between 2006 and 2015 in English with regard to the CSMR and familial/hereditary cancer. The key words used in the search were: illness representations, common sense model, self regulatory model, familial/hereditary/genetic cancer, genetic cancer counseling. The selection of studies followed the PRISMA-P guidelines [24, 25], which suggest a three-stage procedure: in the first stage, studies were selected based on the title, in the second stage, the abstracts of the remaining studies were read and excluded, and, in the final stage, the results section was read (Figure 1). Each member of the research team analyzed all selected titles, abstracts, and then the integral text in order to establish the eligibility of the articles included in the analysis. The disagreements between the reviewers regarding the final selection were resolved by reaching a consensus through discussion.

The studies that we considered relevant were those that used the Common Sense Model (CSM) and/or the Self-Regulatory Model (SRM) as the theoretical background for the analysis of familial cancer (perception/representation of the disease, perceived risk of cancer, worries about cancer, impact of cancer family history, genetic counseling and testing, screening). We included studies focusing on the issue of familial/genetic cancer and those whose results correlate with the CSM and/ or SRM theoretical models, as well as studies in which the CSM and SRM theoretical models are used in genetic counseling for familial/genetic cancers.

We excluded articles structured as reviews, debates, case studies, meta-analyses, posters, conference abstracts, PhD theses/dissertations, pure science, exclusively cellular/laboratory tests, studies published in journals other than the journals ranked by Web of Science, studies where the keywords were found only in the bibliography, studies which included the exclusive analysis of cancers with no hereditary/familial risk, of blood (hematologic) cancers, of other chronic diseases with no hereditary risk, and studies conducted exclusively on health care providers.

The goals, the study population, the theoretical model involved and the main results of each study included in the analysis are presented (Table I).

\section{Results}

The search yielded a total of 1904241 articles. 1904173 of these were excluded when the title/ abstract was analyzed; the following were also excluded: theses, duplicate abstracts of conferences/ congresses, books and articles which could not be accessed in extenso, which led to a remainder of 68 potentially relevant articles. After excluding the reviews, the studies which included several theoretical models without separately analyzing them, 


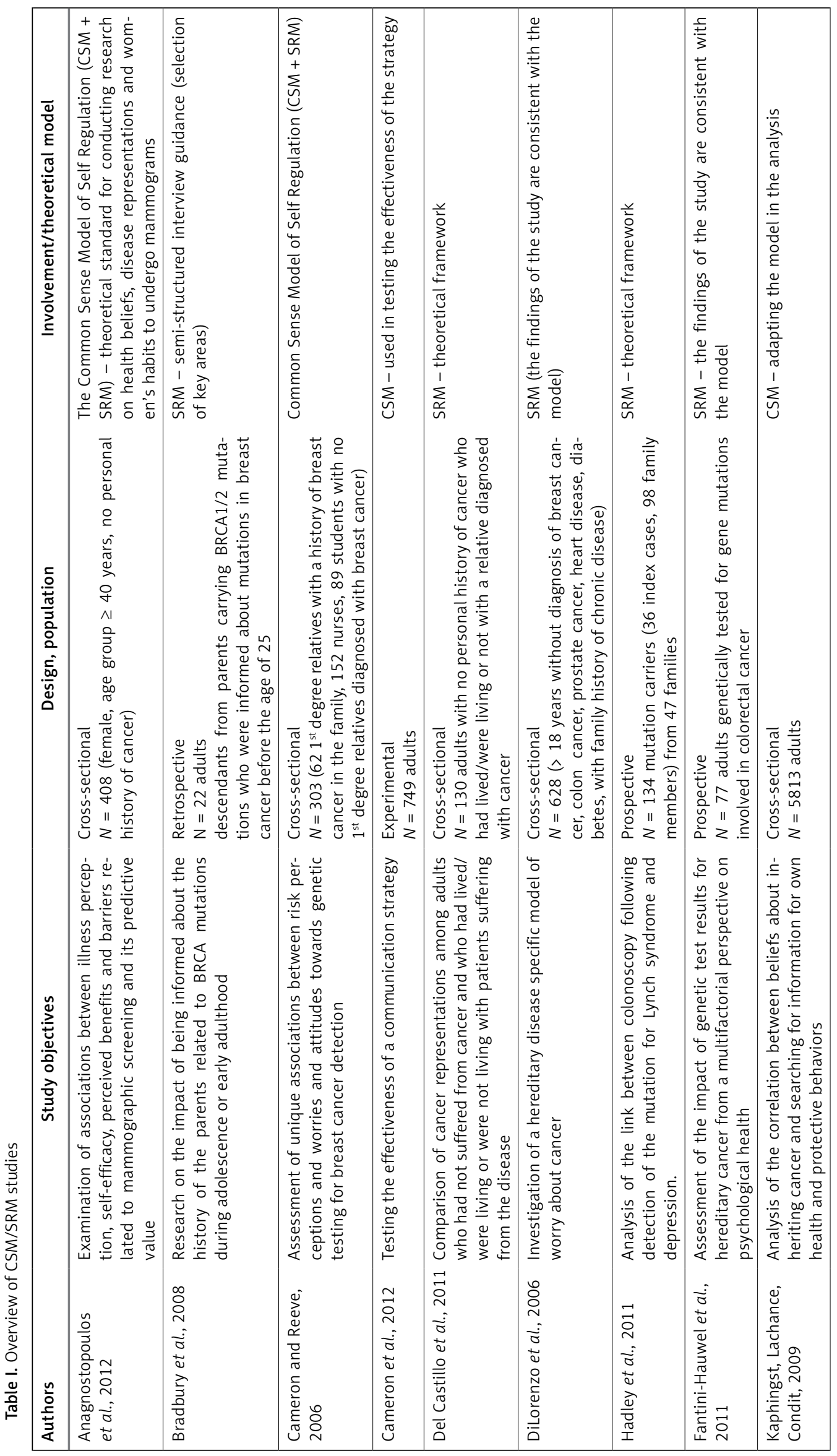




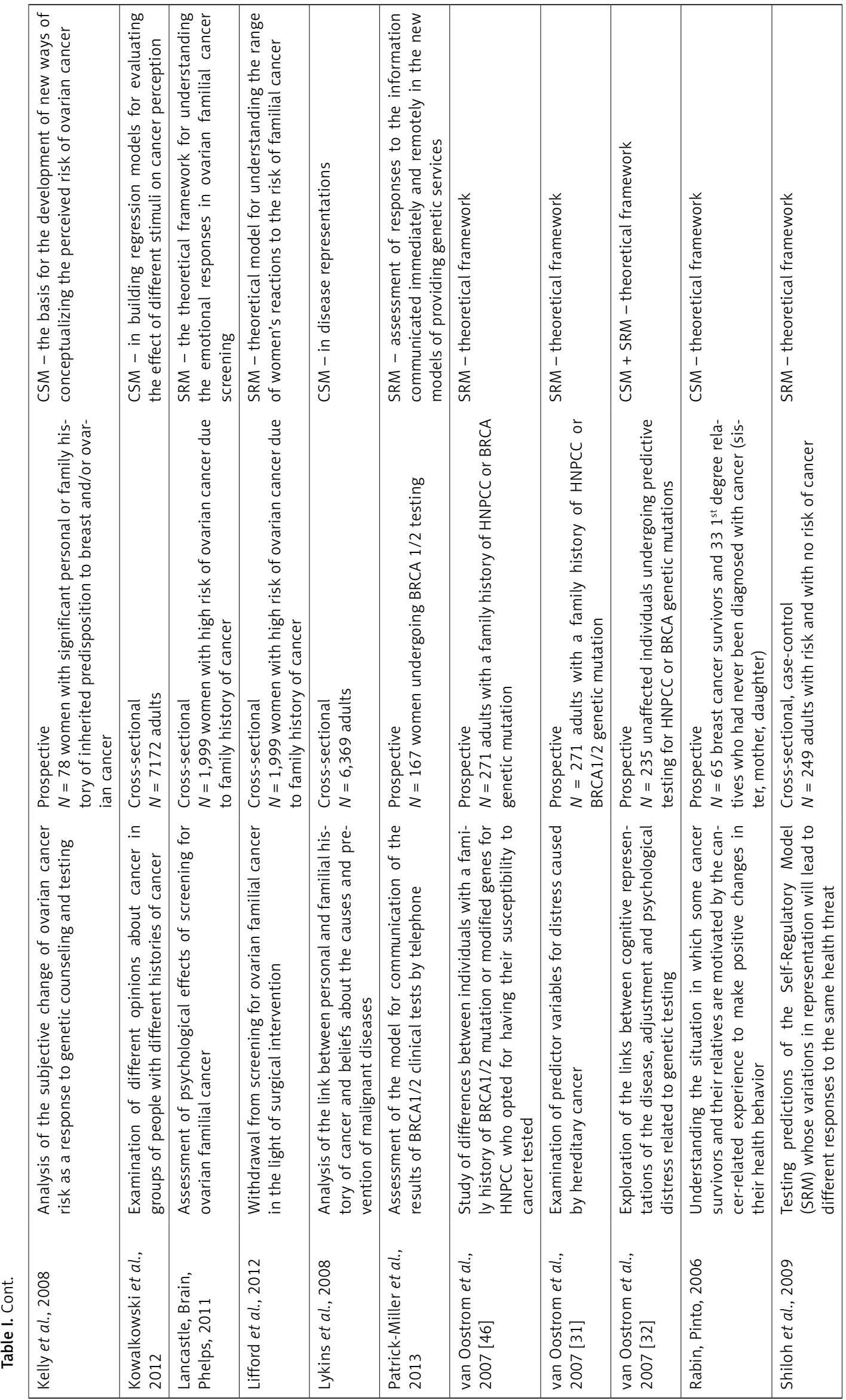


and the study of other chronic diseases (including hematological diseases) and of cancer types without familial/genetic associations, 23 articles remained, which met all the inclusion and exclusion criteria (Figure 1).

Seven (30.4\%) studies included only female subjects, 1 study included only male subjects, while the rest of the studies (69.5\%) included both sexes. All the selected studies included adult subjects ( $>18$ years of age). Regarding the characteristics of the subjects included in the study, most studies (69.5\%) included individuals with heightened risk of cancer due to their family history of cancer/cancer genetic mutation, 2 studies included both individuals with this risk of cancer and individuals with no such risk of cancer, and 5 studies were conducted on subjects from the general population.

Eleven (47.8\%) studies analyzed breast and ovarian cancer ( 6 of them involved BRCA1/2 mutations), 2 studies analyzed exclusively colorectal cancer, and 3 studies covered both BRCA1/2 mutations and gene mutations involved in HNPCC (hereditary nonpolyposis colorectal cancer).

Following the analysis of the 23 articles included in the study, several key themes emphasizing the utility of the CSMR in the psycho-behavioral analysis of familial cancer and genetic testing were identified:

1. Identification of the factors and predictors involved in: compliance with the screening and genetic testing program [26-28]; choosing the response to factors that threaten health and in adopting a healthy lifestyle [29, 30]; emotional distress caused by hereditary cancer [31, 32].

2. Assessment of the psycho-emotional impact, of illness perception and of the perceived risk of cancer in case of screening for genetic cancer [33, 34]; genetic testing and counseling [32, 35-39]; family history of cancer, family history of gene mutations for cancer [30, 40-46].

3. Analysis of particular models for: communication of genetic testing results [36, 47]; worrying about genetic diseases [48].

\section{Factors and predictors involved in the compliance with screening and genetic testing}

Three studies used the CSMR as a theoretical framework for identifying the variables which lead a patient to follow a cancer screening program. Anagnostopoulos [26] and Lifford [28] concluded that individuals, when their health is threatened, develop a cognitive and emotional representation of the disease that causes them to get involved or not in a health monitoring program. In the case of mammographic screening, young age and a family history of breast cancer

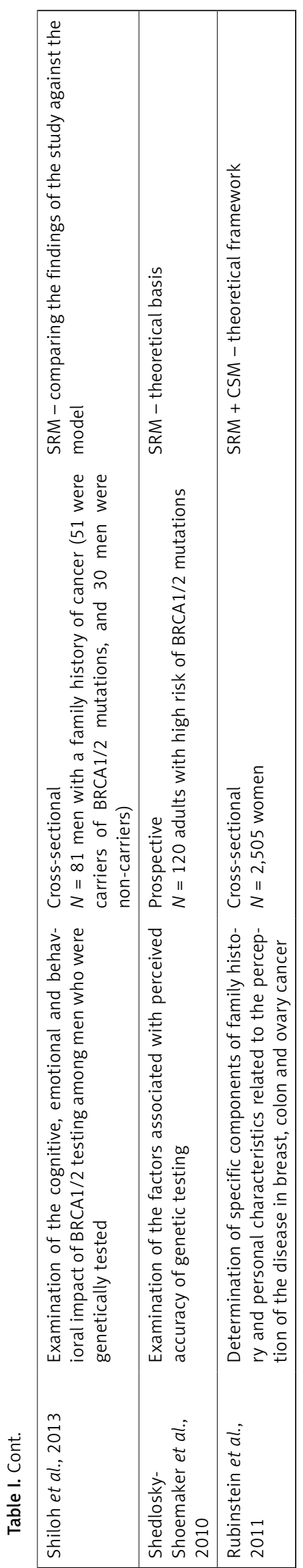


as well as worrying about developing cancer were factors associated with undergoing repeated mammograms throughout life [26]. In the case of screening for ovarian familial cancer, previous experience with cancer, specific distress related to the illness and the belief that aging is a cause of familial cancer were associated with refusal of surgical intervention as a screening procedure for ovarian familial cancer [28].

Worrying about cancer was strongly associated with interest in genetic testing, and with positive beliefs about the benefits of screening, of genetic testing and of prophylactic surgery [27].

Factors that may influence the response to health-threatening factors or the type of adherence to healthy behaviors

Knowing the familial/genetic history of cancer, which is considered to be a factor that could reduce cancer risk, leads the individuals to seek significantly more cancer-related information compared to the average population [29]. In the same study it is shown that heavy smokers who believe that the main cause of lung cancer is genetic are significantly more likely to smoke. In another study conducted on people with heightened risk of cancer, the results showed that smokers were unrealistically optimistic about their health status and cancer-related worries [30].

\section{Predictors of emotional distress caused by familial cancer}

Two prospective studies conducted on subjects undergoing genetic testing, using as a theoretical framework of approach the CSMR, identified predictors of emotional distress caused by hereditary cancer: emotional distress before the testing, hopelessness, the number of first degree relatives affected by cancer and powerful emotional representations of the disease [31].

Both studies [31, 32] show that disease coherence and passive adjustment are predictors of emotional distress caused by hereditary cancer, these factors being useful in anticipating the emotional reactions that the individual may manifest in the case of genetic testing.

\section{Assessment of the emotional impact of screening for hereditary cancer}

In the case of screening for Lynch syndrome, done on carriers of gene mutations, a monitoring colonoscopy may serve as an adjustment strategy in moderating the emotional distress caused by the identification of the susceptible mutation of cancer [33].

However, in the case of screening for ovarian familial cancer, the results of the study conducted on a sample of women with risk of ovarian cancer due to family history of cancer did not reach a conclusion about the predictive usefulness of the variables related to the illness perception in explaining the emotional distress during screening [34]. Almost a fifth of the women were extremely anxious, and more than a quarter reported high levels of emotional distress specific to the ovarian cancer, although they were taking part in a screening program for ovarian cancer [34].

\section{The impact of genetic testing and counseling at a psycho-emotional level and on the perceived risk of cancer}

Fantini-Hauwel et al. [35] measured anxiety as a state comparatively in two groups of patients - carriers and non-carriers of the gene mutation involved in colorectal cancer, before and after the genetic testing. The results of the study revealed that, in the case of non-carriers, the anxiety before the test was strongly correlated with the anxiety after the test. In the case of carriers, no association was found between pre-test and post-test anxiety. Moreover, for the carriers, the communication of the results generated a reorganization of psychological functioning, which was independent of their previous emotional state and mood. In the case of the subjects with alexithymia the difficulty of expressing emotions before the test determined a similar difficulty after the test. Alexithymia, according to the study, is the only predictor of post-test emotional distress for both carriers and non-carriers. For mutation carriers who suffered from alexithymia, the capacity to recognize and express emotions was negatively affected after they received the test results [35].

Patrick-Miller et al. [36] measured anxiety as a state, general depression and anxiety before the test and after the communication of test results for BRCA1/2 by telephone. Anxiety as a state decreased significantly after the communication of test results, but no significant difference could be found in the general anxiety and in the depression levels, and the general anxiety decreased significantly after clinical monitoring.

Van Oostrom et al. [32] evaluated hereditary cancer distress and cancer-related worries in a group of healthy individuals undergoing predictive testing for BRCA1/2 or HNPCC mutations, in a longitudinal study before and after genetic testing. The perception of the disease (IPQ-R [49]) predicted the emotional distress caused by hereditary cancer, as well as cancer-related worries. Emotional distress linked to hereditary cancer increased immediately after they received the results of the testing; yet, 6 months later, they experienced a lower level of worrying than the original one. In terms of cancer-related worries, both carriers 
and non-carriers showed lower levels of worrying 6 months after the disclosure of the results, compared to the original level.

However, in an evaluation done after a maximum of 4 years following genetic testing, Shiloh [37] found that male carriers of BRCA1/2 were significantly more stressed after the testing, that they perceived breast cancer as having fewer emotional consequences and effects on the carrier, and that it was easier to treat (Brief IPQ), [50] compared to males who did not carry the BRCA1/2 mutation. After the disclosure of the genetic testing results, $48 \%$ of the carriers reported that testing increased the perception of their own risk and $74 \%$ of them intensified the screening for cancer.

Nevertheless, Kelly et al. [39] found that in the case of women, especially those with a history of breast cancer, there is an improvement in the accuracy of the evaluation of one's risk for ovarian cancer after the genetic counseling and before the genetic testing (before the genetic counseling, the risk was greatly underestimated). The disclosure of the genetic testing results had only a moderate influence on the accuracy of the evaluation of one's risk for ovarian cancer, as the tendency of underestimating the risk was maintained, especially in women carrying the BRCA1/2 mutation. The percentage of estimated risk for ovarian cancer declined over time, regardless of testing results or history of breast cancer [39].

In a group of people with increased risk for BRCA1/2 gene mutations, Shedlosky-Shoemaker et al. [38] studied in a longitudinal study the change in the perceived accuracy of the cancer risk depending on the perceived accuracy of the genetic testing, which was influenced by genetic counseling. The perceived risk of developing cancer was lower in subjects who showed increased perceived precision of genetic testing after counseling.

\section{The impact of family history of cancer and} of gene mutations on the psycho-emotional state of the individual and on the perceived illness risk

Family history of cancer is associated with different illness perceptions, as revealed by the results of the analyzed studies that used the CSMR as a theoretical framework [41, 42].

In a study conducted on healthy adults living with a relative diagnosed with cancer [41], it was the cancer-related family experience that had the greatest impact both on the emotional status and on the content of cancer-related representations. These results are supported by Kowalkowski et al. [42], who, in his survey, found significant correlations between cancer history and perceptions about cancer, and that having a family history of cancer was more likely to lead to worries about developing the disease in the future. Moreover, family history of cancer led individuals to believe that the disease was most often not caused by their behavior or lifestyle. This belief is present in studies conducted by Bradbury et al. [40], Kaphingst et al. [29] and Shiloh et al. [30], where some of the smokers with cancer risk considered that healthy behavior would not reduce cancer risk when there was genetic susceptibility. However, in Lykins's et al. randomized study [43], for individuals with a personal history of cancer (survivors), the presence of family history of cancer did not affect their tendency to believe in the role that controllable factors (smoking, unhealthy diet, stress, alcohol, lack of exercise) have in influencing the risk of cancer, contrary to the beliefs of individuals with no personal history of cancer, but with a family history of this disease [43]. Rabin and Pinto [44] found no significant difference between breast cancer survivors and their first-degree relatives in the perception of the role of controllable factors in developing cancer.

Rubinstein et al. [45] found that the most significant predictive factor for the perceived risk of breast cancer was having first-degree relatives with breast cancer. The total number of relatives with breast cancer was associated with the perception of a high risk for ovarian cancer and the perception of a reduced capacity of preventing the ovarian cancer. Family history of a particular type of cancer was associated with different perceptions of risk for another type of cancer [40, 42]. Regarding the family history of genetic mutations susceptible to cancer, Bradbury et al. [40], in a retrospective qualitative study conducted on adult descendants from parents who carried BRCA1/2 mutations, found that most descendants believed that the disclosure of information related to genetic mutation history had a significant impact on their emotional status, and that for some individuals it could even lead to a change in their health behavior. Most descendants reported that their interest in genetic counseling or testing increased when they discovered cancer genetic mutations in their parents [40]. Associations between the history of genetic mutations of cancer and the perception of the disease were also found by van Oostrom et al. [46] in a survey of adults with a family history of BRCA1/2 or HNPCC genetic mutation. Individuals from families with BRCA1/2 mutations perceived hereditary cancer as more serious and tended to perceive less control over the disease; at the same time they more often felt significantly overwhelmed by the genetic risk and unable to cope with this risk compared to individuals from families with mutations involved in HNPCC. 
Analysis of models of communication in the context of genetic testing and of models of worry specific to genetic diseases

In an experimental study having the CSMR as a theoretical framework, Cameron et al. [47] tested the effectiveness of a strategy for communicating the information referring to genetic testing and its implications in adhering to an adaptive behavior in the case of a hypothetical test for colon cancer. According to the results of the study, disclosure of information referring to risk actions led to improved risk beliefs about coherence regarding health promoting behaviors. The disclosure of information reduced cancer risk projections compared to those who did not receive this information. Explaining through short messages how the action can reduce the genetic risks may foster beliefs that motivate individuals to take protective measures [47].

In the search for effective models for the communication of genetic testing results, Patrick-Miller et al. - also having the CSMR as a theoretical framework of approach - studied the effect of communicating the results via telephone. The results of the study show that this method cannot be associated with negative emotional and cognitive responses, which could support the inclusion of telephone communication in providing genetic services [36].

Using the CSMR, DiLorenzo et al. [48] investigated a model of worrying specific to colon cancer. According to this model, family history of cancer, the specific risk, and the overall risk of disease influence the level of worry about the disease.

In the systematic analysis of the 23 studies we have highlighted the utility of the CSMR in the analysis of the psycho-behavioral implications of familial cancer for individuals affected by the disease or with high risk for the disease in the screening for familial cancer and in the genetic testing.

Using the CSMR as a theoretical framework of approach, the results of the analyzed studies supported the idea that individuals create their own cognitive and emotional representation of the disease when their health is threatened; this representation is influenced by the presence of a family history of cancer and causes them to adopt or not a salutogenetic behavior [26, 27, 29, 31, 33, 34 , 41, 43, 46, 47]. Disease representations, particularly the cognitive ones, can be predictors of responses to health threats that determine different health behaviors $[29,30]$. Age, family history of cancer, and worrying about the disease are factors associated with undergoing screening for cancer [26-28]. At the same time, the disease representation can cause, according to Cameron and Reeve [27], irrational behavior, withdrawal from screen- ing for cancer, or the preservation of unhealthy behavior. For the time being, no consensus has been reached as to which factors act as predictors of compliance with cancer screening programs, which makes it necessary to conduct more longitudinal studies. Associating the CSMR with decision-making in the analysis may generate a better understanding of the way in which individuals decide to engage or not in cancer screening or genetic testing programs [20]. Further research is recommended on whether individuals who perceive disease as having a genetic cause expose themselves more to carcinogenic agents, behavior which then affects their health.

The perceived risk and worrying about the disease are analyzed through the two parallel systems of representation of the disease - the cognitive and the emotional one - according to the CSMR [3, 27]. Many of the studies included in this review support the role of disease representations in risk perception, and the connection between risk perception and worries about the disease, in the context of family history of cancer or of genetic testing or counseling [28, 30, 32, 37-39, 42, 44, 45, 48]. The dynamics of the CSMR highlight, through the conducted longitudinal studies, the importance of knowing the predictors of emotional distress caused by hereditary cancer, as it is necessary to anticipate the emotional and cognitive reactions that a person might have when being tested for genetic susceptibility to cancer [32], in order to identify the maladaptive representations and their cognitive restructuring [31].

In order to improve the understanding of the connection between the risk for a genetic disease and behavior, Cameron et al. [47] developed an experimental model for information communication, yet these results cannot be generalized, as further studies are necessary in order to generate interventions that are conceptually clear and that can prove their efficiency in adopting salutogenetic behaviors.

The CSMR can be considered to be a useful integrative theoretical framework in understanding and analyzing familial cancer and genetic testing, by emphasizing the distinction between the interactive influences of cognitive and emotional representations related to the perceived risk of cancer and worrying about the disease when there is a family history of cancer, with a predictive role in the adoption of preventive behaviors [27] and assuring quality of life for these patients [51].

\section{Limitations of this review}

Most of the analyzed studies included some limitations, which in some cases led to limitation of accuracy and of generalizability of the results. 
The main general limitation is that only one study is randomized, the rest being studies of series of cases. Therefore, to generalize the results, it is necessary to conduct new studies on larger populations, on individuals from other societies and in various cultural contexts. Another limitation present in $60.8 \%$ of the reviewed studies was their cross-sectional design. Thus, longitudinal studies are needed to explore how perceptions about the disease change over time in response to new influences (personal and/or familial experiences related to the disease), changes in the emotional consequences of genetic testing and the adjustment following genetic testing. To analyze the risk-behavior causality, it is necessary to assess longitudinally the impact of educational activities based on genetic susceptibility or on information concerning the family history of cancer on the disease-related beliefs and how these beliefs affect behavior. A prospective analysis of the factors that predict the withdrawal from screening at different times is also necessary.

\section{Clinical implications}

The findings of this analysis can be used to develop and implement personalized psycho-educational programs aimed at modifying maladaptive representations and negative emotional responses related to familial cancer, reducing the barriers and enhancing the perceived benefits, which would result in increased compliance with treatment and screening programs [52, 53], and increasing the quality of individual, familial and social life.

In conclusion, choosing the CSMR as a useful tool in conceptualizing the analysis of the psycho-behavioral implications of familial cancer is justified, as it undergoes simultaneous cognitive and emotional processing of the threat posed by the disease and, at the same time, it centers on the individual within a specific familial, social and cultural context. Still, further rigorous, longitudinal research is necessary, in order to standardize and validate the explanatory constructs generated by the CSMR in analyzing the psycho-behavioral implications of familial cancer.

\section{Conflict of interest}

The authors declare no conflict of interest.

\section{References}

1. Leventhal H, Meyer D, Nerenz D. The common sense representation of illness danger. In: Rachman $S$ (ed.). Contributions to medical psychology. Vol. 2. Pergamon, New York 1980; 7-30.

2. Leventhal H, Benyamini Y, Brownlee S, et al. Illness representations: theoretical foundations. In: Perceptions of health and illness. Petrie KJ, Weinman JA (eds.). Harwood Academic Publishers, Amsterdam 1997; 19-46.

3. Leventhal H, Brissette I, Leventhal EA. The common-sense model of self-regulation of health and illness. The self-regulation of health and illness behavior. Psychology Press 2003; 1: 42-65.

4. Hochbaum G, Rosenstock I, Kegels S. Health belief model. United States Public Health Service 1952.

5. Rosenstock IM. Historical origins of the health belief model. Health Educ Behav 1974; 2: 328-35.

6. Maiman LA, Becker MH. The Health Belief Model: origins and correlates in psychological theory. Health Educ Behav 1974; 2: 336-53.

7. Fishbein $M$, Ajzen I. Belief, attitudes, intention, and behavior. An introduction to theory and research. Addison-Wesley, Massachussets 1975.

8. Ajzen I. From intentions to actions: a theory of planned behavior. Springer, Berlin, Heidelberg 1985; 11-39.

9. McAndrew LM, Musumeci-Szabó TJ, Mora PA, et al. Using the common sense model to design interventions for the prevention and management of chronic illness threats: from description to process. Br J Health Psychol 2008; 13: 195-204.

10. Zabora J, BrintzenhofeSzoc K, Curbow B, Hooker C, Piantadosi $\mathrm{S}$. The prevalence of psychological distress by cancer site. Psychooncology 2001; 10: 19-28.

11. Okuyama S, Jones W, Ricklefs C, Tran ZV. Psychosocial telephone interventions for patients with cancer and survivors: a systematic review. Psychooncology 2015; 24: 857-70.

12. Daly MB. A family-centered model for sharing genetic risk. J Law Med Ethics 2015; 43: 545-51.

13. Petrie KJ, Broadbent E, Meechan G. Self-regulatory interventions for improving the management of chronic illness. In: The self-regulation of health and illness behaviour. Cameron LD, Leventhal H (eds.). Routledge, London 2008; 257-77.

14. Popa-Vela O, Diaconescu L. Stiintele comportamentului uman (Human Behavioral Sciences). Ed TREI, Bucuresti 2010; 175-93.

15. Negură A, Matei M, Negură L. Ethical issues in communicating results for molecular tests to families with hereditary risk for cancer. Revista Română de Bioetică 2010; 8: 74-83.

16. Diefenbach MA, Hamrick N. Self-regulation and genetic testing. In: The self-regulation of health and illness behavior. Cameron LD, Leventhal H (eds.). Routledge, London 2008; 314-27.

17. Marteau TM, Weinman J. Self-regulation and the behavioural response to DNA risk information: a theoretical analysis and framework for future research. Soc Sci Med 2006; 62: 1360-8.

18. Gooding HC, Organista K, Burack J, Biesecker BB. Genetic susceptibility testing from a stress and coping perspective. Soc Sci Med 2006; 62: 1880-90.

19. Leventhal H, Leventhal EA, Breland JY. Cognitive science speaks to the "common-sense" of chronic illness management. Ann Behav Med 2011; 41: 152-63.

20. Cameron LD, Leventhal $H$. The self-regulation of health and illness behaviour. Psychology Press 2003.

21. Rothman AJ, Kelly KM, Hertel AW, Salovey P, Cameron LD, Leventhal $H$ (eds). The self-regulation of health and illness behaviour. Routledge, New York, NY, USA 2003; 278-96.

22. Munro S, Lewin S, Swart T, Volmink J. A review of health behaviour theories: how useful are these for developing interventions to promote long-term medication ad- 
herence for TB and HIV/AIDS? BMC Public Health 2007; 7: 104.

23. DiMatteo MR. Social support and patient adherence to medical treatment: a meta-analysis. Health Psychol 2004; 23: 207-18.

24. Moher D, Liberati A, Tetzlaff J, Altman DG; PRISMA Group. Preferred reporting items for systematic reviews and meta-analyses: the PRISMA statement. BMJ 2009; 339: b2535.

25. Shamseer L, Moher D, Clarke M, et al. PRISMA-P Group Preferred reporting items for systematic review and meta-analysis protocols (PRISMA-P) 2015: elaboration and explanation. BMJ 2015; 349: g7647.

26. Anagnostopoulos F, Dimitrakaki C, Fitzsimmons D, Potamianos G, Niakas D, Tountas Y. Health beliefs and illness perceptions as related to mammography uptake in randomly selected women in Greece. J Clin Psychol Med Settings 2012; 19: 147-64.

27. Cameron LD, Reeve J. Risk perceptions, worry, and attitudes about genetic testing for breast cancer susceptibility. Psychol Health 2006; 21: 211-30.

28. Lifford KJ, Fraser L, Rosenthal AN, et al. Withdrawal from familial ovarian cancer screening for surgery: findings from a psychological evaluation study (PsyFOCS). Gynecol Oncol 2012; 124: 158-63.

29. Kaphingst KA, Lachance CR, Condit CM. Beliefs about heritability of cancer and health information seeking and preventive behaviors. J Cancer Educat 2009; 24: 351-6.

30. Shiloh S, Drori E, Orr-Urtreger A, Friedman E. Being 'atrisk' for developing cancer: cognitive representations and psychological outcomes. J Behav Med 2009; 32: 197-208.

31. van Oostrom I, Meijers-Heijboer H, Duivenvoorden HJ, et al. Prognostic factors for hereditary cancer distress six months after BRCA1/2 or HNPCC genetic susceptibility testing. Eur J Cancer 2007; 43: 71-7.

32. van Oostrom I, Meijers-Heijboer H, Duivenvoorden HJ, et al. The common sense model of self-regulation and psychological adjustment to predictive genetic testing: a prospective study. Psychooncology 2007; 16: 1121-9.

33. Hadley DW, Ashida S, Jenkins JF, Calzone KA, Kirsch IR, Koehly LM. Colonoscopy use following mutation detection in Lynch syndrome: exploring a role for cancer screening in adaptation. Clin Genet 2011; 79: 321-8.

34. Lancastle D, Brain K, Phelps C. Illness representations and distress in women undergoing screening for familial ovarian cancer. Psychol Health 2011; 26: 1659-77.

35. Fantini-Hauwel C, Dauvier B, Arciszewski T, Antoine P, Manouvrier S. Genetic testing for hereditary cancer: effects of alexithymia and coping strategies on variations in anxiety before and after result disclosure. Psychol Health 2011; 26: 855-73.

36. Patrick-Miller L, Egleston BL, Daly $M$, et al. Implementation and outcomes of telephone disclosure of clinical BRCA1/2 test results. Patient Educat Couns 2013; 93: 413-9.

37. Shiloh S, Dagan E, Friedman I, Blank N, Friedman E. A follow-up study on men tested for BRCA1/BRCA2 mutations: impacts and coping processes. Psychooncology 2013; 22: 417-25.

38. Shedlosky-Shoemaker R, Ngo TL, Ferketich AK, Porter K, Leventha, H, Kelly KM. Exploring perceptions of genetic testing: an examination of perceived accuracy over time. Patient Educat Couns 2010; 78: 34-9.

39. Kelly KM, Senter L, Leventhal H, Ozakinci G, Porter K. Subjective and objective risk of ovarian cancer in Ash- kenazi Jewish women testing for BRCA1/2 mutations. Patient Educat Couns 2008; 70: 135-42.

40. Bradbury AR, Patrick-Miller L, Pawlowski K, et al. Learning of your parent's BRCA mutation during adolescence or early adulthood: a study of offspring experiences. Psychooncology 2009; 18: 200-8.

41. Del Castillo A, Godoy-Izquierdo D, Vázquez ML, Godoy JF. Illness beliefs about cancer among healthy adults who have and have not lived with cancer patients. Int J Behav Med 2011; 18: 342-51.

42. Kowalkowski MA, Hart SL, Du XL, Baraniuk S, Latini DM. Cancer perceptions: implications from the 2007 health information national trends survey. J Cancer Surviv 2012; 6: 287-95.

43. Lykins EL, Graue LO, Brechting EH, Roach AR, Gochett CG, Andrykowski MA. Beliefs about cancer causation and prevention as a function of personal and family history of cancer: a national, population-based study. Psychooncology 2008; 17: 967-74.

44. Rabin C, Pinto B. Cancer-related beliefs and health behavior change among breast cancer survivors and their first-degree relatives. Psychooncology 2006; 15: 701-12.

45. Rubinstein WS, O'Neill SM, Rothrock N, Starzyk EJ, Beaumont JL, Acheson L. Components of family history associated with women's disease perceptions for cancer: a report from the Family Healthware ${ }^{\mathrm{TM}}$ Impact Trial. Genet Med 2011; 13: 52-62.

46. van Oostrom I, Meijers-Heijboer H, Duivenvoorden HJ, et al. Comparison of individuals opting for BRCA $1 / 2$ or HNPCC genetic susceptibility testing with regard to coping, illness perceptions, illness experiences, family system characteristics and hereditary cancer distress. Patient Educat Couns 2007; 65: 58-68.

47. Cameron LD, Marteau TM, Brown PM, Klein WM, Sherman KA. Communication strategies for enhancing understanding of the behavioral implications of genetic and biomarker tests for disease risk: the role of coherence. J Behav Med 2012; 35: 286-98.

48. DiLorenzo TA, Schnur J, Montgomery GH, Erblich J, Winkel G, Bovbjerg DH. A model of disease-specific worry in heritable disease: the influence of family history, perceived risk and worry about other illnesses. J Behav Med 2006; 29: 37-49.

49. Moss-Morris R, Weinman J, Petrie KJ, Horne R, Cameron $L D$, Buick $L$. The revised illness perception questionnaire (IPQ-R). Psychol Health 2002; 17: 1-16.

50. Broadbent E, Petrie KJ, Main J, Weinman J. The brief illness perception questionnaire. J Psychosom Res 2006; 60: 631-7.

51. Rygiel KA, Drozd M, Bułaś L. Care of cancer patients with liver and bone metastases - the place of pharmaceutical care in a balanced plan, focused on the patient's needs and goals. Arch Med Sci 2017; 13: 1483-92.

52. Woźniacki P, Skokowski J, Bartoszek K, Kosowska A, Kalinowski L, Jaśkiewicz J. The impact of the Polish mass breast cancer screening program on prognosis in the Pomeranian Province. Arch Med Sci 2017; 13: 441-7.

53. Kaczka K, Fendler W, Borowiec M, et al. One-step nucleic acid amplification testing in medullary thyroid cancer lymph nodes: a case series. Arch Med Sci 2015; 11 : 137-41. 